\title{
Effects of an injectable long-acting formulation of ivermectin on Onchocerca ochengi in zebu cattle
}

\author{
Michel Boussinesq ${ }^{1, *}$, Peter Enyong ${ }^{2}$, Patrick Chounna-Ndongmo ${ }^{2}$, Abdel-Jelil Njouendou $^{2}$, Sébastien David Pion $^{1}$, \\ Anthony Rech $^{3}$, Christophe Roberge ${ }^{3}$, Georges Gaudriault ${ }^{3, a}$, and Samuel Wanji ${ }^{2}$ \\ ${ }^{1}$ Recherches Translationnelles sur le VIH et les Maladies Infectieuses (TransVIHMI), UMI233 IRD-U1175 INSERM-Université \\ de Montpellier, BP 64501, 34394 Montpellier Cedex 5, France \\ ${ }^{2}$ Research Foundation for Tropical Diseases and the Environment, PO Box 474, Buea, Cameroon \\ ${ }^{3}$ MedinCell S.A., 3 Rue des Frères Lumière, 34830 Jacou, France
}

Received 3 August 2019, Accepted 5 May 2020, Published online 18 May 2020

\begin{abstract}
The availability of a safe macrofilaricidal drug would help to accelerate onchocerciasis elimination. A trial was conducted in Cameroon to evaluate the effects of a subcutaneous injectable long-acting formulation of ivermectin (LAFI) on the microfilariae (mf) and adult stages of Onchocerca ochengi. Ten zebu cattle naturally infected with the parasite were injected subcutaneously with either $500 \mathrm{mg}$ (group A, $N=4$ ), or $1000 \mathrm{mg}$ long-acting ivermectin (group $\mathrm{B}, N=4$ ) or the vehicle (group $\mathrm{C}, N=2$ ). Skin samples were collected from each animal before, and 6,12 , and 24 months after treatment to measure microfilarial densities (MFDs). Nodules excised before, and 6 and 12 months after treatment were examined histologically to assess the adult worms' viability and reproductive status. Blood samples were collected at pre-determined time-points to obtain pharmacokinetic data. Before treatment, the average O. ochengi MFDs were similar in the three groups. Six months after treatment, all animals in groups A and B were free of skin $\mathrm{mf}$, whereas those in group C still showed high MFDs (mean $=324.5 \mathrm{mf} / \mathrm{g}$ ). Only one ivermectin-treated animal (belonging to group A) had skin $\mathrm{mf} 12$ months after treatment $(0.9 \mathrm{mf} / \mathrm{g})$. At 24 months, another animal in group A showed skin $\mathrm{mf}(10.0 \mathrm{mf} / \mathrm{g})$. The histologic examination of nodules at 6 and 12 months showed that LAFI was not macrofilaricidal but had a strong effect on embryogenesis. The new LAFI regimen might be an additional tool to accelerate the elimination of human onchocerciasis in specific settings.
\end{abstract}

Key words: Onchocerciasis, Onchocerca ochengi, Ivermectin, Long-acting formulation, Microfilaricidal effect, Macrofilaricidal effect.

\begin{abstract}
Résumé - Effets d'une formulation injectable d'ivermectine à activité prolongée sur Onchocerca ochengi chez les bovins zébu. La disponibilité d'un médicament macrofilaricide et sans danger permettrait d'accélérer l'élimination de l'onchocercose. Un essai a été mené au Cameroun pour évaluer les effets d'une formulation injectable en souscutané d'ivermectine à activité prolongée (FIAP) sur les microfilaires (mf) et les stades adultes d'Onchocerca ochengi. Dix vaches zébu infectées naturellement par le parasite ont reçu une injection sous-cutanée de $500 \mathrm{mg}$ (groupe $\mathrm{A}, N=4$ ) ou de $1000 \mathrm{mg}$ d'ivermectine à activité prolongée (groupe $\mathrm{B}, N=4$ ) ou le véhicule (groupe $\mathrm{C}$, $N=2$ ). Des échantillons de peau ont été collectés de chaque animal avant, puis 6,12 et 24 mois après traitement pour mesurer les densités microfilariennes (DMF). Des nodules prélevés avant et 6 et 12 mois après traitement ont été examinés histologiquement pour évaluer la viabilité et le statut reproductif des vers adultes. Des échantillons de sang ont été prélevés pour obtenir des données de pharmacocinétique. Avant traitement, les DMF à $O$. ochengi étaient similaires dans les 3 groupes. Six mois après traitement, aucun des animaux des groupes $\mathrm{A}$ et $\mathrm{B}$ ne présentait de $\mathrm{mf}$ dermiques, alors que ceux du groupe $\mathrm{C}$ présentaient encore des DMF élevées (moyenne : $324,5 \mathrm{mf} / \mathrm{g}$ ). Parmi les animaux traités par ivermectine, un seul (du groupe A) avait des mf dermiques 12 mois après traitement $(0,9 \mathrm{mf} / \mathrm{g})$. A 24 mois, un autre animal du groupe A avait des $\mathrm{mf}(10,0 \mathrm{mf} / \mathrm{g})$. L'examen histologique des nodules collectés à 6 et 12 mois montrait que la FIAP n'était pas macrofilaricide mais avait un effet marqué sur l'embryogénèse. La nouvelle FIAP pourrait représenter un outil pour accélérer l'élimination de l'onchocercose dans certaines circonstances spécifiques.
\end{abstract}

*Corresponding author: michel. boussinesq@ird. fr

${ }^{2}$ Present address: Deinove S.A., ZAC Euromédecine II, Cap Sigma, 1682 Rue de la Valsière, 34790 Grabels, France. 


\section{Introduction}

The main control strategy for onchocerciasis is currently based on mass treatment with ivermectin (IVM) targeting the most affected populations, i.e. those (called meso-hyperendemic) where more than $20 \%$ of the adults present subcutaneous nodules containing Onchocerca volvulus adult worms. In Africa, community-directed treatment with IVM (CDTI) has led to the elimination of onchocerciasis as a public health problem in most of the treated areas. However, to reach the new World Health Organization's objective of elimination of the infection [47], interventions might have to be expanded to the so-far untreated hypoendemic zones, and alternative treatment strategies (ATS, i.e., differing from annual CDTI) implemented [11]. Such strategies include the use of new drugs or new formulations of existing drugs.

IVM has two main effects on $O$. volvulus. First, it induces rapid destruction of the larval stage of the parasites (microfilariae [mf]) which are the cause of the immune reactions leading to the ocular and skin manifestations of the disease (microfilaricidal effect). Second, IVM treatment interrupts for 3-4 months the release of new $\mathrm{mf}$ by the adult female worms (embryostatic effect) [8]. However, as IVM has a limited effect on the lifespan of adult worms, CDTI has to be repeated every 6 or 12 months to maintain microfilarial densities (MFD) below the level associated with clinical manifestations. One of the ATSs that could be used to accelerate elimination of onchocerciasis would be to treat the whole population, or only those individuals currently infected with $O$. volvulus, with a macrofilaricidal drug, i.e. a drug that kills or permanently sterilizes the adult worms.

Presently, the only macrofilaricidal drug which can be distributed on a large scale without major risks of adverse effects is doxycycline. Daily treatment with this antibiotic for 4-6 weeks eliminates the Wolbachia symbiotic bacteria present in the adult worms, which leads to the sterilization and progressive death of the latter [45]. The main problem related to this strategy is the duration of the treatment, and research is ongoing to identify other drugs that could be macrofilaricidal using a regimen of two weeks or less. Three candidates have recently been tested as part of phase 1 trials. The first is oxfendazole [1], which belongs to the benzimidazole family and could have the advantage of killing the adult worms without affecting the $\mathrm{mf}$, and thus would not induce adverse effects, particularly in case of coinfection with Loa loa [27, 48]. Ongoing trials (phase 1 and phase 2 against Trichuris trichiura) will enable us to evaluate its possible toxicity [25]. This point is key because the development of another benzimidazole to treat filariases, flubendazole, was interrupted in 2017 because its toxicity associated with effective doses was considered unacceptable [30]. The second macrofilaricidal candidate is emodepside, whose efficacy was demonstrated in pre-clinical trials [29], and which was evaluated in two phase 1 trials, one using single ascending doses [24], and the other using multiple ascending doses (https://clinicaltrials.gov/ct2/show/NCT03383614). The last candidate is a drug called TylAMac (Tylosin Analogue Macrofilaricide, ABBV-4083), which is a macrolide antibiotic effective against Wolbachia [41, 43], and which was also evaluated in a phase 1 trial terminated in 2018 (https://www. dndi.org/diseases-projects/portfolio/abbv-4083/). All these candidates are thus only at an initial stage of clinical development.

The present study was conducted following the observation that three-monthly doses of IVM induce excess mortality in adult worms, when compared to annual doses [22], this excess mortality actually being due to a significant decrease in the adult worms' lifespan [46]. As the plasma half-life of IVM in man ranges between $12 \mathrm{~h}$ and $56 \mathrm{~h}$ following oral administration [26], we hypothesized that longer and continuous exposure of the parasite to the drug could have a stronger macrofilaricidal effect. Presently, several commercial long-acting formulations of IVM exist, one of the best known being the subcutaneous injectable formulation Ivomec ${ }^{\circledR}$ Gold for cattle [15]. In this context, we tested the long-term efficacy (two years) of an injectable long-acting IVM formulation on the cattle-Onchocerca ochengi filarial model. This model is widely used to assess the effects of potentially filaricidal drugs because $O$. ochengi is taxonomically close to $O$. volvulus, and because the adult stages of both species live in subcutaneous nodules [32]. The tested formulation is based on the proprietary drug delivery platform $\mathrm{BEPO}^{\circledR}$, which uses bioresorbable block copolymers as functional excipients to control the release of IVM. In this study, an assessment was made of the effect of the slow release of IVM on the skin MFD by counting mf in skin biopsies, and on the fertility and the viability of the adult worms, by histological examination of sections of excised subcutaneous nodules.

\section{Materials and methods \\ Animals}

Ten Gudali zebu cattle (Bos indicus) were purchased in villages near Ngaoundere (Adamaoua region of Cameroon) where transmission of $O$. ochengi is ongoing [44]. They were selected on the basis of their sex (female), age (three years) and presence of at least 10 subcutaneous nodules between the udder and the umbilicus, and in the inguinal region. The animals were not weighed, and no girth measurement was made to estimate their weight, but given the age of the cows, one can assume that weight ranged between $250 \mathrm{~kg}$ and $330 \mathrm{~kg}$ [2]. They were transported to the field research station of the Research Foundation for Tropical Diseases and the Environment (REFOTDE) located near Modeka, in the South-West region, on the right bank of the Mungo River. Each animal was identified using an individual number printed on labels attached at one ear. The interval of time between the departure of the cows from the Adamaoua region and the first examination round (and administration of treatment) was six weeks.

\section{Treatment description}

The injectable long-acting formulation of IVM was prepared by Medincell using their proprietary drug delivery platform BEPO $^{\circledR}[23,37]$. A diblock (PEG-PLA) and a triblock (PLA-PEG-PLA) bioresorbable copolymer were allowed to dissolve overnight in a biocompatible solvent, dimethyl sulfoxide (DMSO), with gentle mixing on a roller mixer at room temperature. Then, $40 \mathrm{~mL}$ of the obtained 
vehicle were sterile filtered into a $50 \mathrm{~mL}$ glass bottle and kept refrigerated before shipment. The rest of the vehicle (approx. $160 \mathrm{~mL}$ ) was used to prepare the IVM formulation; preweighed IVM powder was added to the vehicle and allowed to gently dissolve on a roller mixer at room temperature. The final solution of IVM was sterile filtered into a $250 \mathrm{~mL}$ glass bottle and kept refrigerated prior to shipment. The composition of the formulation was $7.5 \mathrm{w} / \mathrm{w} \%$ IVM, $40 \mathrm{w} / \mathrm{w} \%$ of copolymers and $52.5 \mathrm{w} / \mathrm{w} \%$ of DMSO.

\section{Treatment and follow-up of adverse effects}

Four animals (group A) were injected subcutaneously, just behind the shoulder, with $500 \mathrm{mg}$ IVM, four others (group B) with $1000 \mathrm{mg}$ IVM, and two others (group C) with the vehicle only. Injections were made by a veterinarian using a 16-gauge needle and the volume injected was about $5.8 \mathrm{~mL}$ for the $500 \mathrm{mg}$ dose or $2 \times 5.8 \mathrm{~mL}$ for the $1000 \mathrm{mg}$ dose $(5.8 \mathrm{~mL}$ behind each shoulder). As the animals' weight was about 250-330 kg, the IVM doses administered in the two treated groups were $1.5-2.0 \mathrm{mg} / \mathrm{kg}$ and $3.0-4.0 \mathrm{mg} / \mathrm{kg}$, respectively. Upon administration, the initially liquid formulation turned into a solid depot in the subcutaneous space, where IVM was released progressively by diffusion through the formed polymeric matrix. Any anomaly at the injection site(s) and relevant clinical signs (apathy, loss of appetite, tremors, locomotion problems, etc.) were monitored during the three days following the injection, and then at day 7 .

\section{Pharmacokinetics}

The blood sampling schedule was the following: in the vehicle group (group C): pre-dose $(-1 \mathrm{~h})$ and no subsequent sampling; in the IVM treated groups: pre-dose $(-1 \mathrm{~h})$ and multiple post-dose sampling (6 h, D2, D7, D14, D30, D90, D150, D180, D240, D300, D330, and D360).

At each time-point, atleast $4 \mathrm{~mL}$ of blood were withdrawn from the jugular vein or from a vein on the tail and transferred in ethylenediaminetetraacetic acid (EDTA) tubes to prevent coagulation. Samples were placed on ice before being centrifuged.

Blood collection tubes were promptly centrifuged at $2500 \times g$ for $10 \mathrm{~min}$ at room temperature and plasma was split in two aliquots of $500 \mu \mathrm{L}$ in previously labelled polypropylene tubes (aliquots A and B (back-up sample)). Tubes with plasma specimens were frozen and stored at $-80{ }^{\circ} \mathrm{C}$ until being shipped in dry ice containers to Europe. The samples were analyzed at the Echevarne Laboratory, Barcelona, Spain, using a liquid chromatography coupled with tandem mass spectrometry (LC/MS/MS) method. The bioanalytical method was validated based on the following criteria (Selectivity, Recovery, Carry-over, Calibration range and Response function, Limit of Quantification, Precision and Accuracy, Dilution Integrity, Matrix effect, Stability in samples, and Reference Solutions Stability). The Liquid Chromatography system was coupled to tandem mass spectrometry (Triple Quadrupole) with Electrospray Probe. Specifically, the chromatography was performed using a Synergi MAX204 RP column $(100 \AA$ A, $100 \times 3 \mathrm{~mm}$,
$2.5 \mu \mathrm{m})$ and a $\mathrm{C} 18$ guard cartridge $(4 \times 2 \mathrm{~mm})$. The mobile phases were: $\mathrm{A}=50 \mathrm{mM}$ ammonium acetate $(\mathrm{pH} 4.5)$ and $\mathrm{B}=$ acetonitrile. The other conditions were: isocratic elution A/B (10:90); flow rate: $0.5 \mathrm{~mL} / \mathrm{min}$; injection volume: $10 \mu \mathrm{L}$; autosampler temperature: $4{ }^{\circ} \mathrm{C}$; column temperature: $40{ }^{\circ} \mathrm{C}$; and flush port: methanol. The detection consisted in multiple reaction monitoring (MRM) in positive mode. IVM was detected for $\mathrm{m} / \mathrm{z} 892.400>307.200$. The lower limit of quantification (LLOQ) for the method used was $0.1 \mathrm{ng}$ of IVM per $\mathrm{mL}$.

The analysis of the pharmacokinetic parameters (mean $C_{\text {max }}, T_{\text {max }}, C_{\text {last }}$, and $\left.\mathrm{AUC}_{0 \text {-tlast }}\right)$ was undertaken with the help of WinNonlin, Phoenix 64, version 8.0 software.

\section{Skin biopsies and nodulectomies}

One skin biopsy was collected from each animal just before the subcutaneous injection (day 0, D0), and another one after 6, 12, and 24 months (M6, M12, and M24). Nodulectomies were performed at the same time as skin biopsies on D0, M6, and M12. To collect these samples, the animals were put in lateral recumbency, on a mattress, and maintained in this position with ropes, for a maximum of $1 \mathrm{~h}$. All sample collections were performed by a veterinarian, after shaving of the skin and under local anaesthesia. Skin biopsies (surface area about $1 \mathrm{~cm}^{2}$ ) were taken from the area between the udder and the umbilicus, i.e. where the $O$. ochengi microfilarial densities are the highest [44]. Nodules were collected surgically. In some instances, more than one nodule was collected from a given animal at a given time-point. Nodules were placed in tubes containing $10 \mathrm{~mL}$ of fixative ( $10 \%$ formalin) until further processing. After nodulectomy, the wound was sutured and the animal received an intramuscular injection of antibiotics (streptomycin and penicillin G) with no action on the Wolbachia bacterial endosymbionts hosted by filariae. Stitches were removed after seven days.

\section{Microscopic examination of skin biopsies}

The skin biopsies were left to incubate for $24 \mathrm{~h}$ at room temperature in 24-well plates, each well containing $300 \mu \mathrm{L}$ of sterile RPMI 1640, and weighed with a $10 \mathrm{mg}$ precision just before examination. The medium containing the $\mathrm{mf}$ which had emerged during the incubation period was pipetted and placed on microscopic slides and examined at $\times 40$ and $\times 100$ magnification. Four species of bovine Onchocerca are present in North Cameroon $(O$. ochengi, O. gutturosa, O. dukei, and $O$. armillata [44]), and $\mathrm{mf}$ were identified according to their size and aspect $[6,44]$. No $\mathrm{mf}$ of $O$. armillata (length: 300$380 \mu \mathrm{m}$; width: 5.0-6.8 $\mu \mathrm{m}$; characteristic bulging anterior end) was seen. Microfilariae of the three other species were observed: $O$. ochengi (length: $280-300 \mu \mathrm{m}$; width: $6-8 \mu \mathrm{m}$; rounded anterior end); $O$. gutturosa (length: 225-270 $\mu \mathrm{m}$; width: 3.5-4.5 $\mu \mathrm{m}$; rounded anterior end and tapering posterior end); and $O$. dukei (length: 220-260 $\mu \mathrm{m}$; width: 5.0-6.5 $\mu \mathrm{m}$; thinner anterior third of the body). Mf of each these three species were counted by two independent microscopists who had no information on the treatment received by the animal from which the biopsy was taken. The individual MFD were calculated as the arithmetic mean of the two counts and 
expressed as the number of $\mathrm{mf}$ per gram of skin. As $\mathrm{mf}$ of $O$. dukei were seen in only one animal at D0, with a low MFD (16.0/g), the results presented below distinguish only $O$. ochengi $\mathrm{mf}$ and "non O. ochengi" (i.e., O. gutturosa + $O$. dukei) $\mathrm{mf}$. The MFD in each treatment group were calculated as the arithmetic means of individual MFD.

\section{Histological processing of nodules and assessment of worm viability and fertility}

The nodules were embedded in paraffin wax, and $6 \mu \mathrm{m}$ sections were stained with hematoxylin and eosin. Two of the authors (MB and SW) examined the sections independently and without having any information on the treatment arm of the animals. The nodules collected at each round of nodulectomies were examined separately. When the observers did not agree on the classification of the worms in a nodule, the slides were re-examined until a consensus was reached.

The reproductive status of the adult worms was assessed by the presence of oocytes and of embryos (morulas, coiled mf, and stretched $\mathrm{mf}$ ). Live embryos were distinguished from degenerating ones [14]. Worms with uteri containing live embryos of any stage were considered fertile.

\section{Results}

\section{Safety}

After injection of the $\sim 5.8 \mathrm{~mL}$ of liquid $(5.8 \mathrm{~mL} \times 2$ for animals treated with $1000 \mathrm{mg}$ IVM), a small bump (diameter: $\sim 1 \mathrm{~cm}$ ) could be palpated at the injection site. No side effects were recorded in any of the cows during the follow-up period.

\section{Pharmacokinetics}

Following the subcutaneous injection of the long-acting formulation of IVM in cattle, the obtained plasma-concentration time profiles were characterized by rapid absorption of the drug associated with a peak plasma concentration $\left(C_{\max }\right)$ followed by sustained plasma concentrations for at least one year (Fig. 1). Mean $C_{\max }, T_{\max }, C_{\text {last }}$ and $\mathrm{AUC}_{0-\text { tlast }}$ are presented in Table 1. As expected, there was a dose-dependent increase in the mean $C_{\max }$ and mean $\mathrm{AUC}_{0-\text { tlast }}$, the $3-4 \mathrm{mg} / \mathrm{kg}$ dose leading to a 2.2 times higher mean $C_{\max }$ and a 2.5 times higher mean $\mathrm{AUC}_{0-\text { tlast }}$ compared to the $1.5-2 \mathrm{mg} / \mathrm{kg}$ dose group. Consequently, steady IVM plasma concentrations were maintained in the range $5.52-10.28 \mathrm{ng} / \mathrm{mL}$ between days 90 and 365 for the $3-4 \mathrm{mg} / \mathrm{kg}$ dose and $1.65-4.15 \mathrm{ng} / \mathrm{mL}$ for the $1.5-2 \mathrm{mg} / \mathrm{kg}$ dose in the same period.

\section{Microfilarial densities}

The individual and mean MFDs for $O$. ochengi are shown in Table 2 and those for non-ochengi Onchocerca are presented in Table 3. At D0, one of the cows of group B (cow number 3) did not present $O$. ochengi mf. After excluding this animal, the mean $O$. ochengi MFDs were $367.0 \mathrm{mf} / \mathrm{g}$ in the nine remaining cows (standard deviation $[\mathrm{SD}]=398.6$ ), and

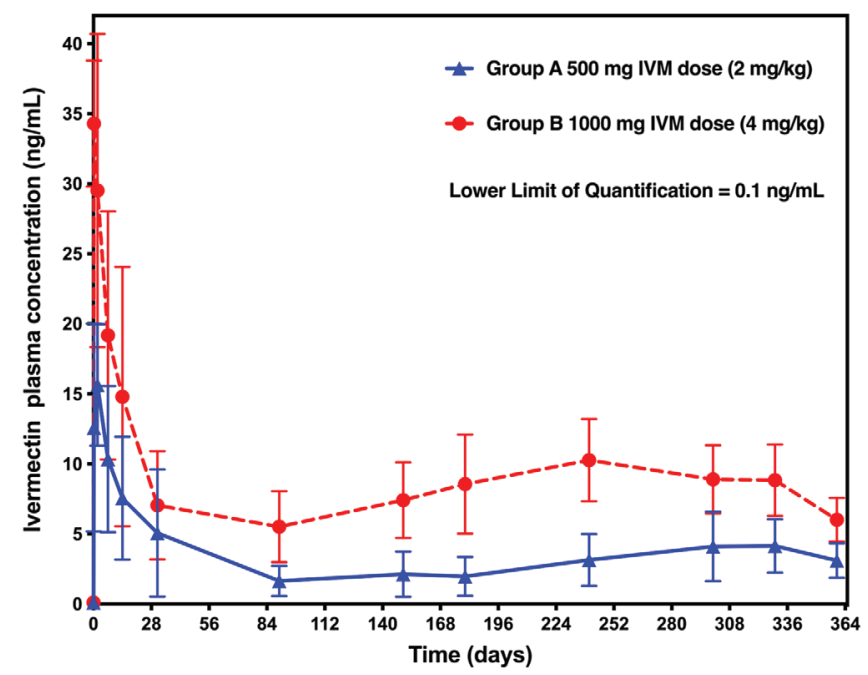

Figure 1. Plasma concentration-time profiles of IVM following subcutaneous injection of a long-acting formulation in cattle $(N=4$ per group). LLOQ = lower limit of quantification.

Table 1. Mean pharmacokinetic (PK) parameters in the two groups of animals treated with IVM.

\begin{tabular}{lccc}
\hline PK parameters & Value & \multicolumn{2}{c}{ Treatment group } \\
\cline { 3 - 4 } & & $500 \mathrm{mg}$ & $1000 \mathrm{mg}$ \\
& & $(1.5-2 \mathrm{mg} / \mathrm{kg})$ & $(3-4 \mathrm{mg} / \mathrm{kg})$ \\
\hline$C_{\max }(\mathrm{ng} / \mathrm{mL})$ & Mean & 16.3 & 36.2 \\
& $\mathrm{SD}$ & 5.4 & 6.9 \\
& $\mathrm{CV}(\%)$ & 33.2 & 19.1 \\
$T_{\max }($ days $)$ & Median & 2.00 & 0.25 \\
$C_{\text {last }}(\mathrm{ng} / \mathrm{mL})$ & Mean & 3.10 & 6.02 \\
& SD & 1.23 & 1.55 \\
$\mathrm{AUC}_{0-\text { tlast }}(\mathrm{ng}$ day $/ \mathrm{mL})$ & Mean & 1239 & 3116 \\
& $\mathrm{SD}$ & 636 & 581 \\
\hline
\end{tabular}

$C_{\max }=$ maximum observed plasma concentration; $T_{\max }=$ time of maximum observed plasma concentration; $C_{\text {last }}=$ last measurable concentration (above the quantification limit); $\mathrm{AUC}_{0-\text { tlast }}=$ area under the concentration-time curve to the last measurable concentration; $\mathrm{SD}=$ standard deviation; $\mathrm{CV}=$ coefficient of variation

$471.6(\mathrm{SD}=540.1), 296.5(\mathrm{SD}=188.2)$, and 263.8 $(\mathrm{SD}=196.2) \mathrm{mf} / \mathrm{g}$ in cows of groups A, B, and C, respectively. The pre-treatment non-ochengi MFDs were 332.3 $(\mathrm{SD}=386.9), 230.9(\mathrm{SD}=193.9)$, and $17.3(\mathrm{SD}=2.6)$ in groups $\mathrm{A}, \mathrm{B}$, and $\mathrm{C}$, respectively.

The $O$. ochengi mean MFD increased gradually from D0 to M24 in animals in group C: $324.5,850.4$, and $1399.0 \mathrm{mf} / \mathrm{g}$ at M6, M12, and M24 (SD = 50.5, 532.9, and 1168.3), respectively. The non-ochengi MFDs in this control group fluctuated between $33.7 \mathrm{mf} / \mathrm{g}$ and $56.7 \mathrm{mf} / \mathrm{g}$.

At M6, no mf (O. ochengi or non-ochengi) was found in the skin samples taken from the cows treated with IVM. At M12, only one animal treated with IVM was found positive for $O$. ochengi, with only one $\mathrm{mf}$ seen in the incubation liquid (MFD: $0.9 \mathrm{mf} / \mathrm{g}$ ). The cow was the one that had the highest pre-treatment MFD and belonged to group A (thus treated with the "low" dose of IVM). At M24, none of the cows treated with 
Table 2. Onchocerca ochengi MFD per gram of skin in each animal and each treatment group at D0, M6, M12, and M24. Post-treatmentpositive results are shown in bold.

\begin{tabular}{|c|c|c|c|c|c|c|c|c|c|c|c|c|c|}
\hline \multirow[t]{2}{*}{ Group $^{a}$} & \multirow[t]{2}{*}{ ID } & \multicolumn{3}{|c|}{ D0 } & \multicolumn{3}{|c|}{ M6 } & \multicolumn{3}{|c|}{ M12 } & \multicolumn{3}{|c|}{ M24 } \\
\hline & & $\mathrm{W}$ & No. Oo & MFD Oo & $\mathrm{W}$ & No. Oo & MFD Oo & $\mathrm{W}$ & No. Oo & MFD Oo & $\mathrm{W}$ & No. Oo & MFD Oo \\
\hline A & 4 & 0.73 & 15 & 20.5 & 0.18 & 0 & 0 & 1.90 & 0 & 0 & 0.92 & 0 & 0 \\
\hline A & 9 & 0.34 & 177 & 520.6 & 0.31 & 0 & 0 & 1.00 & 0 & 0 & 0.70 & 7 & 10.0 \\
\hline A & 28 & 0.25 & 334 & 1336.0 & 0.24 & 0 & 0 & 1.10 & 1 & 0.9 & 0.87 & 0 & 0 \\
\hline \multirow[t]{2}{*}{ A } & 294 & 0.22 & 2 & 9.1 & 0.99 & 0 & 0 & 1.30 & 0 & 0 & 1.47 & 0 & 0 \\
\hline & Mean $^{\text {b }}$ & & & 471.6 & & & 0 & & & 0.2 & & & 2.5 \\
\hline B & 3 & 0.30 & 0 & 0 & 0.44 & 0 & 0 & 1.10 & 0 & 0 & 0.32 & 0 & 0 \\
\hline B & 92 & 0.18 & 6 & 33.3 & 0.30 & 0 & 0 & 1.10 & 0 & 0 & 0.86 & 0 & 0 \\
\hline B & 147 & 0.62 & 287 & 462.9 & 0.47 & 0 & 0 & 0.30 & 0 & 0 & 1.36 & 0 & 0 \\
\hline \multirow[t]{2}{*}{ B } & 255 & 0.44 & 173 & 393.2 & 0.16 & 0 & 0 & 1.50 & 0 & 0 & 0.13 & 0 & 0 \\
\hline & Mean $^{\text {b }}$ & & & 296.5 & & & 0 & & & 0 & & & 0 \\
\hline $\mathrm{C}$ & 254 & 0.45 & 207 & 460.0 & 0.32 & 120 & 375.0 & 0.90 & 1110 & 1233.3 & 0.52 & 120 & 230.8 \\
\hline \multirow[t]{2}{*}{$\mathrm{C}$} & 256 & 0.37 & 25 & 67.6 & 0.50 & 137 & 274.0 & 0.40 & 187 & 467.5 & 0.52 & 1335 & 2567.3 \\
\hline & Mean $^{\mathrm{b}}$ & & & 263.8 & & & 324.5 & & & 850.4 & & & 1399.0 \\
\hline
\end{tabular}

Abbreviations: $\mathrm{ID}=$ animal identity number; $\mathrm{W}=$ weight of skin specimen (in grams); No. Oo = total number of microfilariae of Onchocerca ochengi having emerged from the skin specimen; MFD Oo $=O$. ochengi microfilarial density per gram of skin.

${ }^{\mathrm{a}} \mathrm{A}=500 \mathrm{mg}$ IVM; B = $1000 \mathrm{mg}$ IVM; C = Control (vehicle only).

${ }^{\mathrm{b}}$ Arithmetic mean of the individual Onchocerca ochengi microfilarial densities in the group (in group B, the mean was calculated after excluding animal \#3, which did not present $O$. ochengi microfilariae before treatment).

Table 3. Non-O. ochengi (O. gutturosa and $O$. dukei) MFD per gram of skin in each animal and each treatment group at D0, M6, M12, and M24. Post-treatment-positive results are shown in bold.

\begin{tabular}{|c|c|c|c|c|c|c|c|c|c|c|c|c|c|}
\hline \multirow[t]{2}{*}{ Group $^{a}$} & \multirow[t]{2}{*}{ ID } & \multicolumn{3}{|c|}{ D0 } & \multicolumn{3}{|c|}{ M6 } & \multicolumn{3}{|c|}{ M12 } & \multicolumn{3}{|c|}{ M24 } \\
\hline & & $\mathrm{W}$ & No. Ogd & MFD Ogd & $\mathrm{W}$ & No. Ogd & MFD Ogd & $\mathrm{W}$ & No. Ogd & MFD Ogd & $\mathrm{W}$ & No. Ogd & MFD Ogd \\
\hline $\bar{A}$ & 4 & 0.73 & 2 & 2.7 & 0.18 & 0 & 0 & 1.90 & 0 & 0 & 0.92 & 0 & 0 \\
\hline A & 9 & 0.34 & 90 & 264.7 & 0.31 & 0 & 0 & 1.00 & 0 & 0 & 0.70 & 0 & 0 \\
\hline A & 28 & 0.25 & 20 & 80.0 & 0.24 & 0 & 0 & 1.10 & 0 & 0 & 0.87 & 0 & 0 \\
\hline \multirow[t]{2}{*}{ A } & 294 & 0.22 & 216 & 981.8 & 0.99 & 0 & 0 & 1.30 & 0 & 0 & 1.47 & 0 & 0 \\
\hline & Mean $^{\mathrm{b}}$ & & & 332.3 & & & 0 & & & 0 & & & 0 \\
\hline B & 3 & 0.30 & 11 & 36.7 & 0.44 & 0 & 0 & 1.10 & 0 & 0 & 0.32 & 0 & 0 \\
\hline B & 92 & 0.18 & 92 & 511.1 & 0.30 & 0 & 0 & 1.10 & 0 & 0 & 0.86 & 0 & 0 \\
\hline B & 147 & 0.62 & 40 & 64.5 & 0.47 & 0 & 0 & 0.30 & 0 & 0 & 1.36 & 0 & 0 \\
\hline \multirow[t]{2}{*}{ B } & 255 & 0.44 & 137 & 311.4 & 0.16 & 0 & 0 & 1.50 & 0 & 0 & 0.13 & 0 & 0 \\
\hline & Mean $^{\mathrm{b}}$ & & & 230.9 & & & 0 & & & 0 & & & 0 \\
\hline $\mathrm{C}$ & 254 & 0.45 & 9 & 20.0 & 0.32 & 21 & 65.6 & 0.90 & 0 & 0 & 0.52 & 59 & 113.5 \\
\hline \multirow[t]{2}{*}{$\mathrm{C}$} & 256 & 0.37 & 5 & 14.7 & 0.50 & 7 & 14.0 & 0.40 & 27 & 67.5 & 0.52 & 0 & 0 \\
\hline & Mean $^{\mathrm{b}}$ & & & 17.3 & & & 39.8 & & & 33.7 & & & 56.7 \\
\hline
\end{tabular}

Abbreviations: $\mathrm{ID}=$ animal identity number; $\mathrm{W}=$ weight of skin specimen (in grams); No. Ogd = total number of microfilariae of Onchocerca gutturosa or $O$. dukei having emerged from the skin specimen; MFD Ogd $=O$. gutturosa $+O$. dukei microfilarial density per gram of skin. ${ }^{\mathrm{a}} \mathrm{A}=500 \mathrm{mg}$ IVM; B = $1000 \mathrm{mg}$ IVM; C = Control (vehicle only).

b Arithmetic mean of the individual Onchocerca ochengi microfilarial densities in the group.

IVM showed non-ochengi skin mf but, again, one cow in group A showed O. ochengi $\mathrm{mf}$ (MFD: $10.0 \mathrm{mf} / \mathrm{g}$ ). This cow was the one that had the second highest pre-treatment MFD: $520.6 \mathrm{mf} / \mathrm{g}$. The cow found positive at M12 was negative at M24.

\section{Reproductive status and viability of adult worms}

Sixteen nodules containing 24 female worms were collected on D0, just before treatment. Six of the females (25\%) contained live embryos in their uteri and were thus considered fertile, and $19(79.2 \%)$ contained live embryos or oocytes and were thus fertile or potentially fertile (results in Table 4). Similar percentages (29.0 and $74.2 \%$, respectively) were obtained by combining all the untreated female worms (thus including the worms collected at M6 and M12 from animals in group C).

On M6 and M12, none of the female worms collected from the treated groups $(N=11$ on M6 and 13 on M12) contained live embryos in their uteri. The proportion of potentially fertile females (shedding oocytes), which was fairly high on M6 in the treated groups $(90.9 \%)$, decreased to $38.5 \%$ at M12.

During the course of this study, no dead female worms were observed in the treated groups of cows at M6 and M12 
Table 4. Results of the histological examination of nodules.

\begin{tabular}{|c|c|c|c|c|c|c|c|c|c|}
\hline Time point & $\begin{array}{l}\text { Treatment } \\
\text { group }(s)^{\mathrm{a}}\end{array}$ & $\begin{array}{c}\text { No. } \\
\text { nodules }\end{array}$ & $\begin{array}{l}\text { No. female } \\
\text { worms }\end{array}$ & $\begin{array}{l}\text { No. } \\
\text { fertile }\end{array}$ & $\begin{array}{c}\text { No. shedding } \\
\text { oocytes }\end{array}$ & $\begin{array}{c}\text { No. } \\
\text { empty }\end{array}$ & $\begin{array}{l}\text { No. } \\
\text { dead }\end{array}$ & $\begin{array}{l}\% \text { fertile } \\
\text { females }\end{array}$ & $\begin{array}{c}\% \text { worms fertile } \\
\text { or shedding oocytes }\end{array}$ \\
\hline \multirow[t]{4}{*}{$\overline{\mathrm{D} 0}$} & $\mathrm{~A}$ & 6 & 12 & 1 & 8 & 2 & 1 & 8.3 & 75.0 \\
\hline & B & 6 & 7 & 2 & 3 & 1 & 1 & 28.6 & 71.4 \\
\hline & $\mathrm{C}$ & 5 & 5 & 3 & 2 & 0 & 0 & 60.0 & 100 \\
\hline & $A+B+C$ & 16 & 24 & 6 & 13 & 3 & 2 & 25.0 & 79.2 \\
\hline \multirow[t]{3}{*}{ M6 } & A & 7 & 6 & 0 & 5 & 1 & 0 & 0 & 83.3 \\
\hline & B & 5 & 5 & 0 & 5 & 0 & 0 & 0 & 100 \\
\hline & $\mathrm{C}$ & 3 & 1 & 1 & 0 & 0 & 0 & 100 & 100 \\
\hline \multirow[t]{3}{*}{ M12 } & A & 8 & 8 & 0 & 3 & 5 & 0 & 0 & 37.5 \\
\hline & B & 7 & 5 & 0 & 2 & 3 & 0 & 0 & 40.0 \\
\hline & $\mathrm{C}$ & 5 & 6 & 2 & 1 & 1 & 2 & 33.3 & 50.0 \\
\hline M6 & $A+B$ & 12 & 11 & 0 & 10 & 1 & 0 & 0 & 90.9 \\
\hline M12 & $A+B$ & 15 & 13 & 0 & 5 & 8 & 0 & 0 & 38.5 \\
\hline $\begin{array}{l}\text { All naïve } \\
\text { worms }^{\mathrm{b}}\end{array}$ & & 24 & 31 & 9 & 14 & 4 & 4 & 29.0 & 74.2 \\
\hline
\end{tabular}

${ }^{\text {a }}$ A = $500 \mathrm{mg}$ IVM; B = $1000 \mathrm{mg}$ IVM; C = control (vehicle only).

b All worms (groups A, B, and C) collected at D0 and worms in group C collected at M6 and M12.

(total number of females observed at these time-points: $N=11$ and $N=13$, respectively). Conversely, 4 of the 31 untreated female worms (worms observed at D0 in nodules collected from the three groups, plus worms observed at M6 and M12 in nodules from group C) were dead (12.9\%). These results suggest that the subcutaneous injectable long-acting formulation of IVM did not have a detectable macrofilaricidal effect on the adult worms.

Male worms were not counted because their numbers were very low in the examined histologic sections. In addition, some sections were of sub-optimal quality and enabled only assessment of female worms.

\section{Discussion}

Wahl et al. [44] assessed the anatomic distribution of $O$. ochengi $\mathrm{mf}$ in the hide of eight cows infected with this parasite. At the sites of highest concentration (near the umbilicus and in the inguinal region) the MFD recorded after 4-h incubation in RPMI was $221 \mathrm{mf} / \mathrm{g}$. As the MFD increases by 1.5-2.0 when the incubation time increases from $4 \mathrm{~h}$ to $24 \mathrm{~h}$ [44], this MFD was similar to that recorded during the present study (367.0 mf/g).

Our results show that the in-situ forming depot containing IVM used in this study maintained the Onchocerca sp. mf at extremely low levels for two years. None of the cows treated with IVM presented skin $\mathrm{mf}$ at M6, and only one was mfpositive at M12 (with $0.9 \mathrm{mf} / \mathrm{g}$ ), and another at M24 (with $10.0 \mathrm{mf} / \mathrm{g}$ ). Both the cows with post-treatment-positive biopsies had been treated with the low dose $(500 \mathrm{mg}$ ) of IVM. These results were obtained by examining a single fairly large biopsy (180-730 mg), and not smaller biopsies (mean weight: $54 \mathrm{mg}$ ) taken from three different sites, as done in another study [36]. By doing so (mainly to limit the time the animals were held down in an uncomfortable position), we could not account for variation in MFD in the skin [44], but given the considerable decrease in the MFD observed in the IVM-treated animals, the results would have probably been similar by examining more than one biopsy.

Interestingly, in cows in group $\mathrm{C}$, the MFD increased gradually from D0 to M24, both for $O$. ochengi (from $264 \mathrm{mf} / \mathrm{g}$ to $1399 \mathrm{mf} / \mathrm{g}$ ) and non-O. ochengi (from $17.3 \mathrm{mf} / \mathrm{g}$ to $56.7 \mathrm{mf} / \mathrm{g}$ ). As the REFOTDE field research station is located in an area where there is probably no transmission of bovine Onchocerca spp., this increase might be due to the fact that pre-adult or young adult stages which were present at D0 developed during the following two years to adult worms producing $\mathrm{mf}$. This increase in the MFD in group $\mathrm{C}$ makes the persistent absence of $\mathrm{mf}$ for two years in most of the cows in groups $\mathrm{A}$ and $\mathrm{B}$ even more remarkable.

The possibility that the decrease in the MFD could be due, at last partly, to other treatments received by the animals before their departure from the Adamaoua region has to be considered. Even though little quantitative information is available on the veterinary drug market in this area, it is known that levamisole, albendazole and IVM are widely used by cattle herders to treat intestinal nematode infections in their animals [20]. Levamisole has no significant effect on the microfilariae and macrofilariae of $O$. volvulus [3], and this is probably also the case for $O$. ochengi. A single dose of albendazole $(400 \mathrm{mg})$ has little effect on the $O$. volvulus MFD and adult-worm reproductive activity [5], but treatment with $800 \mathrm{mg}$ daily for three or seven days, or with $1200 \mathrm{mg}$ daily for three days leads to a gradual decrease in the MFDs, which are reduced by $24-66 \%$ one year after treatment [4]; the latter regimens have no macrofilaricidal effect, and the effect on the MFD is due to an embryotoxic effect (i.e., preventing the embryos from developing in the uteri to the stretched $\mathrm{mf}$ stage). Regarding IVM, it is known that O. volvulus MFDs are reduced by $99 \%$ of pre-treatment levels 1-2 months after treatment, and then re-increase progressively [8]. As the dynamics are probably similar for $O$. ochengi [36], if the drug had been given just before the animals' departure from the Adamaoua region, then the O. ochengi MFD would have been close to their nadir when the cows underwent pre-treatment biopsy six weeks later. As most of the study 
animals showed significant $O$. ochengi or non-ochengi MFD at that time, we can assume that they had not been treated with IVM recently; and should this be the case, then such treatment could not explain the subsequent decrease in the MFD. These considerations, together with the fact that the substantial decrease in the MFD was seen only in those cows that received IVM, lead us to believe that any treatment received by the animals before the study had only a minimal influence, if any, on the results observed.

The prolonged effect of the formulation on the MFD could be due to an embryotoxic (see above) and/or an embryostatic effect (preventing the release of $\mathrm{mf}$ from the adult female worms), and/or a persisting microfilaricidal effect (destruction of the mf after their release from the females' uteri), and/or a macrofilaricidal effect (killing of the adult worms). As the main objective of the study was to investigate the effects of the formulation on the adult worms, we did not collect skin samples within the first weeks following treatment to evaluate the (probable) microfilaricidal effect. The histologic examination of nodules collected at M6 and M12 provided information on the effects of the formulation on the adult worms' viability and reproductive status. This showed that all the female worms collected at M6 and M12 from the cows treated with IVM were alive, showing that the formulation had no macrofilaricidal effect. These results are similar to those obtained, also using the bovine- $O$. ochengi model, with repeated monthly doses of subcutaneous IVM at $500 \mu \mathrm{g} / \mathrm{kg}$ [12]. However, the females from animals treated with IVM did not contain live embryos in their uteri, demonstrating that the treatment had a strong effect on the parasite's fertility. In addition, the fact that the proportion of worms shedding oocytes decreased markedly between M6 and M12 suggests that permanent exposure to IVM for one year might sterilize the worms. No nodules were collected at M24, but the fact that one (and only one) cow treated with IVM showed skin $\mathrm{mf}$ at that time-point suggests that the condition of the worms at M24 was probably similar to that observed at M12.

Given these results, one may wonder what role the in-situ forming depot evaluated as part of this study could play to accelerate the elimination of human onchocerciasis, and thus whether it would be worth assessing this formulation in phase 1 clinical trials. The long-term effect of the IVM-releasing depot on $O$. ochengi MFD was remarkable and a comparable effect would probably be obtained with $O$. volvulus. However, a similar effect on the MFD, and thus on the transmission of $O$. volvulus, could be obtained with annual oral treatment with moxidectin (MOX), a drug whose plasma half-life is 20-43 days, i.e. much longer than that of IVM (12-56 h) [35]. The question to be answered is "what would be the advantage of treating with an injectable long-acting formulation of IVM, instead of annual oral doses of MOX?" As IVM seems to have a prophylactic effect on Onchocerca sp. [40, 42], i.e. prevents the development of the parasite up to the adult stage, a sustained-release formulation might protect people from new infections for many months. A solid implant containing IVM was shown to be effective in preventing experimental infection of dogs with Dirofilaria immitis larvae [18]. The prophylactic effect of MOX on Onchocerca sp. is unknown. Injectable long-acting formulations of MOX (ProHeart 6 and ProHeart 12) are used to prevent canine infection with $D$. immitis [34] but, given the half-life of the drug, oral treatment with MOX would probably need to be repeated every 2-3 months to have any prophylactic effect against $O$. volvulus. In this case, an IVMcontaining subcutaneous depot might be advantageous. The prophylactic effect of an injectable long-acting formulation of IVM on $O$. ochengi could be tested using the same protocol as that used for IVM [42], i.e. by comparing the incidence of infection in two groups of calves living in an area where the parasite is transmitted, one treated with the IVM formulation, and one receiving only the vehicle.

In addition, macrocyclic lactones like IVM and MOX are also effective against soil-transmitted helminths (STH) and ectoparasites such as scabies and lice [7]. A yearly single subcutaneous injection of a long-acting formulation of IVM might be as efficient to prevent clinical manifestations of STH as two- or three-monthly doses of MOX. Regarding scabies, in vitro assays suggest that the concentration of MOX required to kill the mites might be lower than that of IVM [33], and trials using a porcine model suggest that a single oral dose of MOX is more effective than two consecutive IVM doses [10]. Collateral benefits of a sustained-release formulation of IVM would also include an effect on the longevity of mosquitoes and other insects biting treated people. Studies are being conducted to develop long-acting formulations of IVM that could help decrease the density of Anopheles sp. and thus the transmission of malaria, and an oral ultra-long-acting drug delivery system containing IVM was developed to reach this objective [9]. A subcutaneous IVM-releasing depot could have the same effect, with the significant advantage of showing sustained release over up to a year. In addition, when the malaria vectors are zoophagic, treatment of cattle could play a significant role toward reducing vector density, and thus malaria transmission [16]. Conversely, repeated doses of MOX might well have little impact on malaria transmission because MOX seems to be less active than IVM on malaria vectors [13, 21].

The fact that the long-acting formulation of IVM used as part of this study does not seem to be macrofilaricidal for $O$. volvulus is disappointing. However, it seems to sterilize the female worms, and this, added to other effects against soil-transmitted helminths and some ectoparasites and vectors of serious diseases like malaria, makes the concept of a longacting formulation of IVM a potentially highly valuable alternative to the existing methods, including the use of oral IVM (and/or MOX) tablets.

Of course, any decision regarding treatment with longacting formulations has to be taken considering possible risks associated with long-term exposure to these drugs. For IVM long-acting formulations, one of the risks is the possible accelerated selection of IVM-resistant parasites, including Onchocerca sp. or intestinal nematodes [39]. Studies have suggested that the embryostatic effect of IVM against $O$. volvulus could be reduced in populations treated repeatedly with IVM, but this phenomenon might not be due to genetic selection, but to other processes that remain to be clarified [19]. Regarding intestinal nematodes, the risk of resistance is certainly higher than for filariae, but it could be prevented by treating the host simultaneously with another anthelmintic such as a benzimidazole. The second point to consider is the management 
of drug-drug interactions (DDIs) in subjects already treated with another drug, or who have to start treatment with another drug after injection of the IVM long-acting formulation. A review of the interactions of IVM (and other macrocyclic lactones) with ATP-binding cassette transporters suggests that co-administration of IVM with drugs such as the antifungal drug ketoconazole, the antihypertensive, and antiarrhythmic drug verapamil, or the anti-diarrheal drug loperamide can increase the IVM AUC by 2-fold [31]. In addition, in vitro or animal model studies suggest possible DDIs between IVM and antibiotics or antiretroviral drugs, and further investigations should be conducted to investigate the possibility of in vivo interactions in humans [28]. This being said, one must recall here that the depot formed by the IVM-long acting formulation used as part of this study can be easily removed if necessary, to prevent adverse effects due to DDIs.

Presently, the major indications for subcutaneous implantable devices or injectable long-acting formulations in humans include contraception (implants containing levonorgestrel or etonogestrel or in-situ formed depots containing medroxyprogesterone acetate (MPA)), treatment of schizophrenia (in-situ formed depot containing risperidone), treatment of prostate cancer (implants or depot containing goserelin, leuprolide, or histrelin), and treatment of opioid abuse (in-situ formed depot containing buprenorphine) [38]. Sayana ${ }^{\circledR}$ Press, a formulation containing $104 \mathrm{mg}$ MPA in a $0.65 \mathrm{~mL}$ suspension and which can be injected subcutaneously by trained community health workers or self-injected, is a very popular family planning method in Africa [17]. More than one million doses have been used so far. It would certainly be useful to conduct socioanthropologic studies in population where onchocerciasis and malaria are endemic to evaluate the acceptability of a subcutaneous injection of a long-acting formulation of IVM that is fully bioresorbable and would therefore not require depot removal upon completion of the release period.

\section{Conflicts of interest}

The patent related to the formulation used during this study belongs to MedinCell S.A. There is no conflict of interest between the co-authors and present or past affiliation with MedinCell and the co-authors affiliated at the Institut de Recherche pour le Développement (IRD) and the Research Foundation for Tropical Diseases and the Environment (REFODTE). Co-authors affiliated with IRD or REFODTE have no specific interest (i.e., shares) or commercial relationship (i.e., consulting) with MedinCell. In the event of a commercial development of the long-acting formulation of IVM described in the present publication, MedinCell would benefit from the outcomes of the present study. However, the co-authors with present or past affiliation at MedinCell did not contribute to the examination of the skin samples or the onchocercal nodules collected as part of this study, nor to the data analysis and interpretation of results.

Acknowledgements. This study was co-funded by the Institut de Recherche pour le Développement (IRD, Marseille, France), MedinCell (Jacou, France) and the Research Foundation for Tropical Diseases and the Environment (REFOTDE, Buea, Cameroon).
We thank the REFOTDE personnel for their help in the field, as well as Dr. Elizabeth Hene, veterinarian, and Lucy Enow and Emilia Ayompe, veterinary assistants, for having performed the skin snips and the nodulectomies of the animals. We thank the personnel of the Echevarne Laboratory, Barcelona, Spain, for having performed the pharmacokinetic analyses.

\section{References}

1. An G, Murry DJ, Gajurel K, Bach T, Deye G, Stebounova LV, Codd EE, Horton J, Gonzalez AE, Garcia HH, Ince D, Hodgson-Zingman D, Nomicos EYH, Conrad T, Kennedy J, Jones W, Gilman RH, Winokur P. 2019. Pharmacokinetics, safety, and tolerability of oxfendazole in healthy volunteers: a randomized, placebo-controlled first-in-human single-dose Escalation Study. Antimicrobial Agents and Chemotherapy, 63, e02255-18.

2. Assana E, Doba E, Awah-Ndukum J, Soh GB, Mohamadou A, Mebanga AS, Zoli AP. 2018. Formule de barymétrie pour l'estimation du poids chez les zébus Goudali au Cameroun. Bulletin of Animal Health and Production in Africa, 66, 469-480.

3. Awadzi K, Schulz-Key H, Howells RE, Haddock DR, Gilles HM. 1982. The chemotherapy of onchocerciasis. VIII. Levamisole and its combination with the benzimidazoles. Annals of Tropical Medicine and Parasitology, 76, 459-473.

4. Awadzi K, Hero M, Opoku O, Büttner DW, Gilles HM. 1991. The chemotherapy of onchocerciasis. XV. Studies with albendazole. Tropical Medicine and Parasitology, 42, 356-360.

5. Awadzi K, Edwards G, Duke BO, Opoku NO, Attah SK, Addy ET, Ardrey AE, Quartey BT. 2003. The co-administration of ivermectin and albendazole - safety, pharmacokinetics and efficacy against Onchocerca volvulus. Annals of Tropical Medicine and Parasitology, 97, 165-178.

6. Bain O. 1981. Le genre Onchocerca : hypothèses sur son évolution et clé dichotomique des espèces. Annales de Parasitologie Humaine et Comparée, 56, 503-526.

7. Barda B, Ame SM, Ali SM, Albonico M, Puchkov M, Huwyler J, Hattendorf J, Keiser J. 2018. Efficacy and tolerability of moxidectin alone and in co-administration with albendazole and tribendimidine versus albendazole plus oxantel pamoate against Trichuris trichiura infections: a randomised, non-inferiority, single-blind trial. Lancet Infectious Diseases, $18,864-873$.

8. Basáñez MG, Pion SD, Boakes E, Filipe JA, Churcher TS, Boussinesq M. 2008. Effect of single-dose ivermectin on Onchocerca volvulus: a systematic review and meta-analysis. Lancet Infectious Diseases, 8, 310-322.

9. Bellinger AM, Jafari M, Grant TM, Zhang S, Slater HC, Wenger EA, Mo S, Lee YL, Mazdiyasni H, Kogan L, Barman R, Cleveland C, Booth L, Bensel T, Minahan D, Hurowitz HM, Tai T, Daily J, Nikolic B, Wood L, Eckhoff PA, Langer R, Traverso G. 2016. Oral, ultra-long-lasting drug delivery: application toward malaria elimination goals. Science Translational Medicine, 8,365 ra157.

10. Bernigaud C, Fang F, Fischer K, Lespine A, Aho LS, Dreau D, Kelly A, Sutra JF, Moreau F, Lilin T, Botterel F, Guillot J, Chosidow O. 2016. Preclinical study of single-dose moxidectin, a new oral treatment for scabies: efficacy, safety, and pharmacokinetics compared to two-dose ivermectin in a porcine model. PLoS Neglected Tropical Diseases, 10, e0005030.

11. Boussinesq M, Fobi G, Kuesel AC. 2018. Alternative treatment strategies to accelerate the elimination of onchocerciasis. International Health, 10(Suppl. 1), i40-i48. 
12. Bronsvoort BM, Renz A, Tchakouté V, Tanya VN, Ekale D, Trees AJ. 2005. Repeated high doses of avermectins cause prolonged sterilisation, but do not kill, Onchocerca ochengi adult worms in African cattle. Filaria Journal, 4, 8.

13. Butters MP, Kobylinski KC, Deus KM, da Silva IM, Gray M, Sylla M, Foy BD. 2012. Comparative evaluation of systemic drugs for their effects against Anopheles gambiae. Acta Tropica, 121, 34-43.

14. Büttner DW, Albiez EJ, von Essen J, Erichsen J. 1988. Histological examination of adult Onchocerca volvulus and comparison with the collagenase technique. Tropical Medicine and Parasitology, 39(Suppl. 4), 390-417.

15. Cady SM, Cheifetz PM, Galeska I. 2013. Veterinary long-acting injections and implants, in Long Acting Animal Health Drug Products, Rathborne MJ, McDowell A, Editors. Springer: Boston, MA. p. 271-294.

16. Chaccour CJ, Ngha'bi K, Abizanda G, Irigoyen Barrio A, Aldaz A, Okumu F, Slater H, Del Pozo JL, Killeen G. 2018. Targeting cattle for malaria elimination: marked reduction of Anopheles arabiensis survival for over six months using a slowrelease ivermectin implant formulation. Parasites and Vectors, 11, 287.

17. Cover J, Blanton E, Ndiaye D, Walugembe F, Lamontagne DS. 2014. Operational assessments of Sayana ${ }^{\circledR}$ Press provision in Senegal and Uganda. Contraception, 89, 374-378.

18. Cunningham CP, Brown JM, Jacobson GA, Brandon MR, Martinod SR. 2006. Evaluation of a covered-rod silicone implant containing ivermectin for long-term prevention of heartworm infection in dogs. American Journal of Veterinary Research, 67, 1564-1569.

19. Doyle SR, Bourguinat C, Nana-Djeunga HC, Kengne-Ouafo JA, Pion SDS, Bopda J, Kamgno J, Wanji S, Che H, Kuesel AC, Walker M, Basáñez MG, Boakye DA, Osei-Atweneboana MY, Boussinesq M, Prichard RK, Grant WN. 2017. Genomewide analysis of ivermectin response by Onchocerca volvulus reveals that genetic drift and soft selective sweeps contribute to loss of drug sensitivity. PLoS Neglected Tropical Diseases, 11, e0005816.

20. Ebene Njongui J, Onyali Ikechuku O, Mingoas JP, Mfopit Mouliom Y, Aboubakar Dandjouma AK, Manchang TK, Toukala JP, Akuro A, Nwosu CO. 2016. Management of cattle parasitism and use of anthelmintics in mixed farming systems in the Vina Division, Cameroon. International Journal of Livestock Research, 6, 59-72.

21. Fritz ML, Walker ED, Miller JR. 2012. Lethal and sublethal effects of avermectin/milbemycin parasiticides on the African malaria vector, Anopheles arabiensis. Journal of Medical Entomology, 49, 326-331.

22. Gardon J, Boussinesq M, Kamgno J, Gardon-Wendel N, Demanga-Ngangue Duke BO. 2002. Effects of standard and high doses of ivermectin on adult worms of Onchocerca volvulus: a randomised controlled trial. Lancet, 360, 203-210.

23. Gaudriault G, Inventor. 2011. Biodegradable drug delivery compositions. US Patent 9,023,897 B2.

24. Gillon JYA, van den Berg F, Dequatre Cheeseman K, Hopchet N, Delhomme S, Peña Rossi C, Monnot F, StrubWourgaft N, Rodriguez ML, Don R. 2018. A single-center, first-in-human, randomized, double-blind, placebo-controlled, parallel-group study to investigate the safety, tolerability and pharmacokinetics of escalading doses of emodepside (BAY444400 ) in healthy male subjects. American Journal of Tropical Medicine and Hygiene, 99(Suppl. 4), 168.

25. Gonzalez AE, Codd EE, Horton J, Garcia HH, Gilman RH. 2019. Oxfendazole: a promising agent for the treatment and control of helminth infections in humans. Expert Review of Anti-Infective Therapy, 17, 51-56.
26. Guzzo CA, Furtek CI, Porras AG, Chen C, Tipping R, Clineschmidt CM, Sciberras DG, Hsieh JY, Lasseter KC. 2002. Safety, tolerability, and pharmacokinetics of escalating high doses of ivermectin in healthy adult subjects. Journal of Clinical Pharmacology, 42, 1122-1133.

27. Hübner MP, Martin C, Specht S, Koschel M, Dubben B, Frohberger SJ, Ehrens A, Fendler M, Struever D, VallarinoLhermitte N, Gokool S, Townson S, Hoerauf A, Scandale I. 2018. Oxfendazole treatment has a macrofilaricidal efficacy against the filarial nematode Litomosoides sigmodontis in vivo and inhibits Onchocerca gutturosa adult worm motility in vitro. American Journal of Tropical Medicine and Hygiene, 99(Suppl. 4), 656-657.

28. Kigen G, Edwards G. 2017. Drug-transporter mediated interactions between anthelminthic and antiretroviral drugs across the Caco-2 cell monolayers. BMC Pharmacology and Toxicology, $18,20$.

29. Kulke D, Townson S, Bloemker D, Frohberger S, Specht S, Scandale I, Glenschek-Sieberth M, Harder A, Hoerauf A, Hübner MP. 2017. Comparison of the in vitro susceptibility to emodepside of microfilariae, third stage larvae and adult worms of related filarial nematodes. American Journal of Tropical Medicine and Hygiene, 97(Suppl. 5), 563.

30. Lachau-Durand S, Lammens L, van der Leede BJ, Van Gompel J, Bailey G, Engelen M, Lampo A. 2019. Preclinical toxicity and pharmacokinetics of a new orally bioavailable flubendazole formulation and the impact for clinical trials and risk/benefit to patients. PLoS Neglected Tropical Diseases, 13, e0007026.

31. Lespine A, Alvinerie M, Vercruysse J, Prichard RK, Geldhof P. 2008. ABC transporter modulation: a strategy to enhance the activity of macrocyclic lactone anthelmintics. Trends in Parasitology, 24, 293-298.

32. Makepeace BL, Tanya VN. 2016. 25 years of the Onchocerca ochengi model. Trends in Parasitology, 32, 966-978.

33. Mounsey KE, Walton SF, Innes A, Cash-Deans S, McCarthy JS. 2017. In vitro efficacy of moxidectin versus ivermectin against Sarcoptes scabiei. Antimicrobial Agents and Chemotherapy, 61, e00381-17.

34. Nolan TJ, Lok JB. 2012. Macrocyclic lactones in the treatment and control of parasitism in small companion animals. Current Pharmaceutical Biotechnology, 13, 1078-1094.

35. Opoku NO, Bakajika DK, Kanza EM, Howard H, Mambandu GL, Nyathirombo A, Nigo MM, Kasonia K, Masembe SL, Mumbere M, Kataliko K, Larbelee JP, Kpawor M, Bolay KM, Bolay F, Asare S, Attah SK, Olipoh G, Vaillant M, Halleux CM, Kuesel AC. 2018. Single dose moxidectin versus ivermectin for Onchocerca volvulus infection in Ghana, Liberia, and the Democratic Republic of the Congo: a randomised, controlled, double-blind phase 3 trial. Lancet, 392, 1207-1216.

36. Renz A, Trees AJ, Achu-Kwi D, Edwards G, Wahl G. 1995. Evaluation of suramin, ivermectin and CGP 20376 in a new macrofilaricidal drug screen, Onchocerca ochengi in African cattle. Tropical Medicine and Parasitology, 46, 31-37.

37. Roberge C, Cros JM, Serindoux J, Cagnon ME, Samuel R, Vrlinic T, Berto P, Rech A, Richard J, Lopez-Noriega A. 2020. BEPO $^{\circledR}$ : bioresorbable diblock mPEG-PDLLA and triblock PDLLA-PEG-PDLLA based in situ forming depots with flexible drug delivery kinetics modulation. Journal of Controlled Release, 319, 416-427.

38. Stewart S, Domínguez-Robles J, Donnelly R, Larrañeta E. 2018. Implantable polymeric drug delivery devices: classification, manufacture, materials, and clinical applications. Polymers, 10, 1379.

39. Sutherland IA, Leathwick DM. 2011. Anthelmintic resistance in nematode parasites of cattle: a global issue? Trends in Parasitology, 27, 176-181. 
40. Taylor HR, Trpis M, Cupp EW, Brotman B, Newland HS, Soboslay PT, Greene BM. 1988. Ivermectin prophylaxis against experimental Onchocerca volvulus infection in chimpanzees. American Journal of Tropical Medicine and Hygiene, 39, 86-90.

41. Taylor MJ, von Geldern TW, Ford L, Hübner MP, Marsh K, Johnston KL, Sjoberg HT, Specht S, Pionnier N, Tyrer HE, Clare RH, Cook DAN, Murphy E, Steven A, Archer J, Bloemker D, Lenz F, Koschel M, Ehrens A, Metuge HM, Chunda VC, Ndongmo Chounna PW, Njouendou AJ, Fombad FF, Carr R, Morton HE, Aljayyoussi G, Hoerauf A, Wanji S, Kempf DJ, Turner JD, Ward SA. 2019. Preclinical development of an oral anti-Wolbachia macrolide drug for the treatment of lymphatic filariasis and onchocerciasis. Science Translational Medicine, 11, eaau2086.

42. Tchakouté VL, Bronsvoort M, Tanya V, Renz A, Trees AJ. 1999. Chemoprophylaxis of Onchocerca infections: in a controlled, prospective study ivermectin prevents calves becoming infected with $O$. ochengi. Parasitology, 118(Pt 2), 195-199.

43. von Geldern TW, Morton HE, Clark RF, Brown BS, Johnston KL, Ford L, Specht S, Carr RA, Stolarik DF, Ma J, Rieser MJ, Struever D, Frohberger SJ, Koschel M, Ehrens A, Turner JD, Hübner MP, Hoerauf A, Taylor MJ, Ward SA, Marsh K, Kempf DJ. 2019. Discovery of ABBV-4083, a novel analog of Tylosin
A that has potent anti-Wolbachia and anti-filarial activity. PLoS Neglected Tropical Diseases, 13, e0007159.

44. Wahl G, Achu-Kwi MD, Mbah D, Dawa O, Renz A. 1994. Bovine onchocercosis in North Cameroon. Veterinary Parasitology, 52, 297-311.

45. Walker M, Specht S, Churcher TS, Hoerauf A, Taylor MJ, Basáñez MG. 2015. Therapeutic efficacy and macrofilaricidal activity of doxycycline for the treatment of river blindness. Clinical Infectious Diseases, 60, 1199-1207.

46. Walker M, Pion SDS, Fang H, Gardon J, Kamgno J, Basáñez MG, Boussinesq M. 2017. Macrofilaricidal efficacy of repeated doses of ivermectin for the treatment of river blindness. Clinical Infectious Diseases, 65, 2026-2034.

47. World Health Organization. 2012. Accelerating work to overcome the global impact of neglected tropical diseases: a roadmap for implementation: executive summary. Geneva: World Health Organization. WHO/HTM/NTD/2012.1.

48. Zahner H, Schares G. 1993. Experimental chemotherapy of filariasis: comparative evaluation of the efficacy of filaricidal compounds in Mastomys coucha infected with Litomosoides carinii, Acanthocheilonema viteae, Brugia malayi and B. pahangi. Acta Tropica, 52, 221-266.

Cite this article as: Boussinesq M, Enyong P, Chounna-Ndongmo P, Njouendou A-J, Pion SD, Rech A, Roberge C, Gaudriault G \& Wanji S. 2020. Effects of an injectable long-acting formulation of ivermectin on Onchocerca ochengi in zebu cattle. Parasite $27,36$.

\section{PARASTIE}

An international open-access, peer-reviewed, online journal publishing high quality papers on all aspects of human and animal parasitology

Reviews, articles and short notes may be submitted. Fields include, but are not limited to: general, medical and veterinary parasitology; morphology, including ultrastructure; parasite systematics, including entomology, acarology, helminthology and protistology, and molecular analyses; molecular biology and biochemistry; immunology of parasitic diseases; host-parasite relationships; ecology and life history of parasites; epidemiology; therapeutics; new diagnostic tools.

All papers in Parasite are published in English. Manuscripts should have a broad interest and must not have been published or submitted elsewhere. No limit is imposed on the length of manuscripts.

Parasite (open-access) continues Parasite (print and online editions, 1994-2012) and Annales de Parasitologie Humaine et Comparée (1923-1993) and is the official journal of the Société Française de Parasitologie. 